\title{
The ontogeny of kin-recognition mechanisms in Belding's ground squirrels
}

Jill M. Mateo

Department of Psychology, Uris Hall, Cornell University, Ithaca, NY 14853-7601, USA

Permanent address: Department of Comparative Human Development \& Committee on Evolutionary Biology, 1126 East 59th Street, The University of Chicago, Chicago, Illinois 60637, USA jmateo@uchicago.edu

\begin{abstract}
Despite extensive research on the functions and mechanisms of kin recognition, little is known about developmental changes in the abilities mediating such recognition. Belding's ground squirrels, Urocitellus beldingi, use at least two mechanisms of kin recognition in nepotistic contexts: familiarity and phenotype matching. Because recognition templates develop from early associations with familiar kin (and/or with self), familiarity-based recognition should precede phenotype-matching recognition even though one template is thought to be used for both mechanisms. I used a cross-fostering design to produce individuals that differed in relatedness and familiarity. Two pups (one female and one male) were exchanged reciprocally between two litters within 48-h of birth. Every five days, from 15 to 30-d of age, young were exposed to bedding and oral-gland odors from their familiar foster mother and an unfamiliar unrelated female (familiarity test) and from their unfamiliar genetic mother and another unfamiliar unrelated female (phenotype-matching test). As expected, discrimination of odors based on familiarity was evident at all ages tested, whereas discrimination based on relatedness was not evident until 30-d. My results provide a first estimate for when phenotype-matching mechanisms are used by young Belding's ground squirrels, and thus when they can recognize unfamiliar kin such as older sisters or grandmothers. Belding's ground squirrels are the first species for which the development of the production, perception and action components are well understood.
\end{abstract}


Keywords: development; kin recognition mechanisms; phenotype matching; odors; Belding's ground squirrels; Urocitellus beldingi

\section{Introduction}

Recognition of conspecifics is mediated through olfactory cues in a variety of taxa (insects: $[1,2]$; amphibians: [3]; fish: [4, 5]; birds: [6, 7]; mammals: [8-10]), including ground-dwelling squirrels [11-13]. In mammals, olfaction is often the primary sensory modality for species, sex, kin and individual recognition [8-10, 14-16]. Odor cues mediate social recognition in Belding's ground squirrels, Urocitellus beldingi, and can be used to discriminate both individuals and kin classes [17, 18]. Kin recognition is an unobservable internal process of assessing genetic relatedness that is inferred on the basis of kin discrimination, the observable differential treatment of conspecifics based on cues that correlate with relatedness. Kin-discrimination processes are conceptualized as three components: the production of cues that can be used for recognition (such as unique odors, plumage patterns, or vocalizations); the perception of these cues by others, in particular how these cues correspond with a stored memory of familiar individuals' cues (a recognition template); and the action taken by an animal if an individual's cues do or do not match its template [see 19].

Several kin recognition mechanisms have been proposed [20-24], but here I focus on two. First, recognition may be based on prior association, referred to simply as familiarity. Animals learn the phenotypes of related individuals they are exposed to early in development (e.g. parents, siblings), and later discriminate these familiar individuals from unfamiliar animals. Second, an individual may learn its own phenotype and/or the phenotype(s) of kin they are exposed to in early development, and later compare or match the phenotypes of unidentified animals to this learned template; this mechanism is known as phenotype matching. Note that phenotype matching requires a correlation between phenotypic and genotypic similarity, regardless of the phenotypes' origins, so that individuals with traits that most 
closely match an animal's template are its closest kin. Both mechanisms involve a comparison between encountered phenotypes and learned templates, but familiarity allows recognition of previously encountered familiar individuals, whereas unfamiliar kin can be identified via the phenotype-matching mechanism $[19,21,23]$.

Despite extensive research on the functions and mechanisms of kin recognition [e.g. 25-31], little is known about ontogenetic changes in the mechanisms mediating such recognition. Several studies have examined changes in preferences for familiar and unfamiliar social cues during early development [3239], and some have studied developmental changes in the role of kinship in social preferences [34, 35, 40, 41]. Even fewer studies have examined the development of recognition cues [but see 3, 42-49]. Here I tested the development of the perceptual component of kin recognition in a study system for which the action component is well understood $[29,50]$.

Belding's ground squirrels are group-living, burrowing rodents found in alpine and subalpine regions of the western United States [51]. They are active above ground between April and August and hibernate the remainder of the year. Each mother produces one litter annually of 5-8 pups, which is reared for 25-28 days in an underground burrow (the natal burrow). Young first come above ground (they 'emerge') as nearly weaned, 4-week old juveniles [52]. Because females nest in equal proximity to close and distant kin, juveniles emerge into a social environment that includes unfamiliar juveniles and adults that vary in genetic relatedness [50]. Two to three weeks after natal emergence, juvenile females establish their own burrow system within $25 \mathrm{~m}$ of their natal burrow, whereas juvenile males begin to disperse permanently from their birthplace [53]. Nasal investigations typically precede social interactions and involve investigation of secretions from apocrine glands located in the mouth corner (oral odors). Dorsal-gland odors (from a field of small apocrine glands along the back) and oral odors are both individually distinct and kin distinct, and they are the primary cues used for social recognition and scent marking [17, 18]. Odors from pedal and anal glands, as well as from the supraorbital region, are also individually distinct [18]. 
Because females are philopatric and live an average of 3.4 years [up to 12 years; 52 ; J. M. Mateo, unpublished data] they live near and frequently encounter other female kin, favoring the evolution of nepotism among females [54]. This includes alarm-call production and cooperative territory defense, with such behaviors directed to close female kin only, such as mothers, sisters, and daughters [29]. In both nepotistic and mate-choice contexts, adult ground squirrels use familiarity and phenotype-matching mechanisms to differentiate relatedness among conspecifics [23, 55; J. M. Mateo, unpubl. data]. Both oral- and dorsal-gland odors co-vary directly with genetic relatedness, allowing all individuals to discriminate among a variety of male and female kin classes, such as aunts, cousins, and non-kin [17].

Juveniles also use familiarity and phenotype-matching mechanisms. For example, in the early weeks after natal emergence they preferentially play with littermates over non-littermates, discriminate between full and half-siblings, and recognize unfamiliar kin [55]. However, it is unclear at what age(s) these abilities develop. Young start producing recognition odors that mediate these behaviors just before first emergence from the natal burrow. These odors become individually distinct and stable shortly after emergence, perhaps because of the switch to a solid diet [42].

Young Belding's ground squirrels first become familiar with their littermates and their mother in the natal burrow, and although another adult may enter the cryptic natal burrow, young do not regularly encounter unfamiliar kin and non-kin until after natal emergence [23, 55]. Using a cross-fostering design [56], I tested when kin-recognition mechanisms develop in young. Because the template used for recognition of unfamiliar kin develops from early associations with familiar kin (and/or with the self), I expected familiarity-based recognition to precede the development of phenotype-matching recognition [even though one template is thought to be used for both mechanisms; 19, 56, 57]. That is, to have the most accurate recognition template, multiple individuals ('referents') will be represented in the template [57-59], thus the ability to generalize from the template during the phenotype-matching process might be delayed until all referents' kin labels are fully developed. Therefore young should demonstrate discrimination of their familiar foster mother from an unfamiliar mother (both unrelated to the young; 
'familiarity test') before they can discriminate between their unfamiliar genetic mother and an unfamiliar unrelated mother ('phenotype-matching test').

\section{Material and Methods}

\subsection{Animals}

I studied ground squirrels in the summer of 2000 at the Sierra Nevada Aquatic Research Laboratory (SNARL; near Mammoth Lakes, CA, USA). I live-trapped pregnant females from a site in Rock Creek Canyon (2834 m), and near Trumbull Lake (2895 m) and Junction Creek Campground (2990 m), CA and housed them in a laboratory building at SNARL where they gave birth and reared their young. Due to trapping distances between females (>200 m, up to $70 \mathrm{~km}$ ), mothers were unlikely to have been closely related [50; J. M. Mateo, unpublished observations of female natal dispersal and male spatial patterns during mating]. Mothers were housed singly in stainless steel cages $(61 \times 45 \times 35 \mathrm{~cm})$ that included a nest box $(28 \times 20 \times 20 \mathrm{~cm})$ fitted with a 6-cm diameter entry hole and a removable top. Females gave birth and reared their young in this nest box, which contained wood shavings for bedding. I also provided mothers with paper towels that they took into their nest box and shredded, creating a fluffy, full nest. I gave animals Purina mouse chow (\#5015) and water ad libitum and occasionally supplemented the food with dandelions, vegetables and sunflower seeds. All animals were maintained on similar diets to minimize environmental influences on odors [e.g. 60]. I maintained the building on a 14:10 h light:dark schedule, which approximated natural conditions, with temperature regulated by a combination of a heater, portable air conditioner and automatic fans $\left(28^{\circ}-41^{\circ} \mathrm{C}\right)$. I refer to 'pups' as $<25$-d old young that would be still confined to their natal burrow if in the wild, 'juveniles' as $\geq 25$-d old young that would have emerged from their natal burrow, and 'adults' as animals $\geq 1$-yr old. 
Using a cross-fostering design I produced individuals that differed in relatedness and familiarity [56]. Two pups (one female and one male) were exchanged reciprocally between two litters born within 48-h of birth. For example, two pups from Mother A would be transferred to Mother B, and two pups from Mother B would be transferred to Mother A. A total of 15 litters were fostered (six pairs and one trio of reciprocal crosses), with 27 pups tested for odor-discrimination abilities. Three cross-fostered pups died before testing began.

Note that it is theoretically possible that young learned their genetic mother's odor prenatally or prior to transfer [e.g. 61], yet it is unlikely that a complex odor such as this is learned this early due to the perinatal status of the olfactory system of rodents [62-64]. Also note that all animals were housed in one laboratory building, which is also where testing took place. For most mothers, an empty cage was adjacent to them, minimizing the likelihood of young learning the odors of nearby adults. When Belding's ground squirrels smell each other, there is typically direct contact with oral glands [65; pers. obs.], and during odor discrimination tasks, animals are typically within $2 \mathrm{~cm}$ of a stimulus [e.g. 18], suggesting that being in the same room likely did not make young familiar with adults other than their foster mother.

This study was approved by Cornell University's Center for Research Animal Resources (protocol \#00-32) and University of California at Santa Barbara's Animal Resource Center (protocol \#5-99-513), and adhered to standards set forth by the NIH for animal research.

\subsection{Preference tests}

Every five days from 15 to 30 days of age, young were tested with bedding and oral-gland odors from their familiar foster mother and an unfamiliar, unrelated female (familiarity test) and from their unfamiliar, genetic mother and a different unfamiliar, unrelated female (phenotype-matching test). Typically, Belding's ground squirrels attend to unfamiliar or novel odors longer than familiar odors [adults or juveniles after emergence; e.g. 17, 18]; however, like the young of some other rodent species [e.g. 37, 38], here, odors that were familiar or that matched recognition templates more closely were 
investigated longer by young squirrels than odors that were unfamiliar or matched templates less well (see Results). Regardless of the direction of the difference, a significant difference indicates discrimination.

I began testing at 15-d because a preference for familiar conspecifics appears to develop between 18 and $23 \mathrm{~d}$ of age [66], and because pups begin to behaviorally discriminate among odors at this age [67; pers. obs.]. Younger pups were not assayed because pilot tests showed they remained too immobile to exhibit discrimination.

Odors were collected by one individual who wore latex gloves to prevent the transfer of human odors to the equipment. One person collected oral odors by swiping $3-\mathrm{cm}^{3}$ polyethylene cubes eight times anterior-posteriorally along both mouth corners $\leq 15$ min before each test [see 17, 18, 42]. Soiled bedding from the nest box was also collected [to include additional distinct odors and a familiar substrate; 18], and the cube and bedding were placed in a $10 \times 4 \times 1 \mathrm{~cm}$ hardware-cloth basket. Because we collected from the top of the nest ball, the bedding likely only had odor from the mother due to her nest building activities. Each basket was placed inside a plastic cage $(38 \times 33 \times 18 \mathrm{~cm}), 8 \mathrm{~cm}$ from the midline. Placement of the two stimuli (e.g. from the genetic mother and unrelated mother) on either side of the cage was arbitrarily determined, and was coded such that other observers did not know the identity of the odor donors.

The pup was placed at the midline of the cage and its behavior videotaped for three minutes on a Sony Digital8 HandyCam camcorder mounted on a tripod adjacent to the cage. The latency to investigate each basket (pup's nose within $1 \mathrm{~cm}$ of a basket or inside the basket) and the total duration of contact (time spent smelling an odor) were recorded by an observer blind to which odors were in the baskets. These data were quantified to the nearest $0.01 \mathrm{sec}$ from videotapes using Ethos 22 event-recorder software (G. Gerstner, unpublished computer program). Cubes, baskets and cages were washed with hot water and unscented soap after use and allowed to air dry.

\subsection{Statistical analyses}


Animals were included in the analysis for each test if they investigated at least one cube. Differential investigation of classes of odors, such as kin versus non-kin, was interpreted as spontaneous discrimination of the odors, reflecting an animal's perceptual ability to assess correlates of relatedness and 'recognize' unfamiliar kin. Because the latency to investigate odors and the duration of investigations were not normally distributed and traditional transformations were not successful, I used two-tailed normal scores tests for these analyses. This test is similar conceptually to a paired $t$ test because the difference between two matched data sets (e.g. investigation of familiar and unfamiliar odors) is normalized and compared against a null hypothesis that the mean difference is zero [68], and is more powerful than a Wilcoxon signed-ranks test for many data sets [69]. Because biologically and statistically I am asking whether, at a given age, young squirrels demonstrate an ability to discriminate two odors, I did not adjust the alpha value $(\alpha=0.05)$ to control for multiple tests.

\section{Results}

\subsection{Familiarity mechanism}

At all four ages, there were no significant differences in the latency to investigate the two odors (Table 1). However, at all ages, young investigated the odor of the familiar foster mother significantly longer than the unfamiliar, unrelated mother (15 days: $t(24)=3.275, p=0.003 ; 20$ days: $t(25)=2.187$, $p=0.038 ; 25$ days: $t(25)=3.719, p=0.001 ; 30$ days: $t(19)=2.261, p=0.036$; Fig. 1 ).

\subsection{Phenotype-matching mechanism}

At all four ages, there were no significant differences in the latency to investigate the two odors (Table 2). At ages 15-25 days, there was no significant difference in the duration of investigation of odors from the unfamiliar genetic mother and the unfamiliar unrelated mother $(15$ days: $t(21)=0.605, p=0.551$; 
20 days: $t(25)=1.908, p=0.068 ; 25$ days: $t(25)=0.680, p=0.503)$. However, at 30 days of age, there was a significant difference, $t(19)=2.176, p=0.042$ (Fig. 2); young ground squirrels investigated the odor of unfamiliar genetic mothers longer than they investigated the odor of unfamiliar unrelated mothers.

\section{Discussion}

Juvenile social interactions are thought to lay a foundation for nepotistic behaviors in adulthood [70, 71], so kin-recognition abilities are expected to develop during their first year. Young ground squirrels start to produce recognition odors prior to natal emergence, but these are not individually distinct until just after emergence [42]. Here I showed that the familiarity mechanism for kin recognition was developed prior to emergence, being evident as early as 15 days of age, with ground squirrels preferring familiar odors (Fig. 1). Results for phenotype-mechanism abilities were similar, with many ground squirrels tending to prefer odors of their genetic mother, but significant discrimination was not evident until after the age of emergence, at 30 days (Fig. 2). My results provide a first estimate for when juveniles in the field can recognize unfamiliar kin such as paternal half-siblings or grandmothers via phenotype matching. It is important to note that a lack of different treatment (here, differential investigation) cannot be interpreted as a lack of recognition ability $[19,24]$. Thus it is possible that young have the perceptual ability to discriminate odors via phenotype matching before they do so behaviorally, although given the fact that they show discrimination based on familiarity at earlier ages, this possibility seems unlikely. Recall that females direct nepotism toward close female kin only [mothers, littermate sisters and nonlittermate sisters; 50], despite being able to recognize other classes of kin using phenotype matching [17, 72].

Proximately, the difference in the developmental onset of the two recognition mechanisms may be related to the development of recognition odors, which do not become stable until about 28 days of age [42]. Therefore juveniles need to continually update their recognition templates during early development, but can use familiarity to recognize their mother and their littermates prior to emergence. Only after 
emergence, however, can juveniles compare the odors of unfamiliar individuals to their now fully formed templates and identify kin via phenotype matching.

Ultimately, the timing of the onset of phenotype-matching abilities may be adaptive because it coincides with when juveniles begin to encounter unfamiliar kin, after they emerge from the natal burrow and move around the meadow. That summer, they will play preferentially with close kin over distant kin and with distant kin over non-kin [55, 73; see also 58], and since juvenile social relationships are thought to lay a foundation for adult nepotism [71], being able to distinguish among cousins, half-siblings and non-kin could be beneficial. Prior to emergence, they only encounter littermates and their mother, so a familiarity-based recognition would be sufficient, although motorically there is little young can do if an unfamiliar individual [potentially infanticidal; 74] enters the natal burrow.

Different kin-recognition mechanisms may be utilized in different contexts, such as mate choice and nepotism, depending on the ecology and sociality of the species $[23,75,76]$. Familiarity may be sufficient for kin recognition in most nepotistic contexts because mothers, daughters and littermate sisters are often the targets for preferential treatment [29, 50; see also 4, 77-79]. However, phenotype matching may be important for recognizing older, non-littermate sisters, or for mate choice to avoid close inbreeding. With the data presented here, we now understand the development of all three components of kin recognition in Belding's ground squirrels, which to my knowledge is the only species for which this is true. Additional experimental data are needed from other biological systems that vary in ecological and social contexts, to determine the relevant selective forces and proximate constraints governing the evolution of the components of kin recognition.

\section{Disclosure statement}

I have no competing interests.

\section{Acknowledgments}


The data collection and analysis were supported by the National Science Foundation (IBN 98-08704). I

thank Katrina Dryer and Chiao-Sze Tsang for assistance in data collection. I had permits from California Fish \& Game and the United States Forest Service. 
Figure 1. Mean (+SE sec) duration of investigation of odors collected from adult female Belding's ground squirrels by young across early development from 15-30 days of age in the familiarity-mechanism test. Black bars represent investigation of odor collected from the familiar foster mother, and open bars represent investigation of odor collected from an unfamiliar unrelated mother. Asterisks indicate significant differences in the duration of investigation of odors $\left(* p<0.05,{ }^{*} p<0.01\right)$.

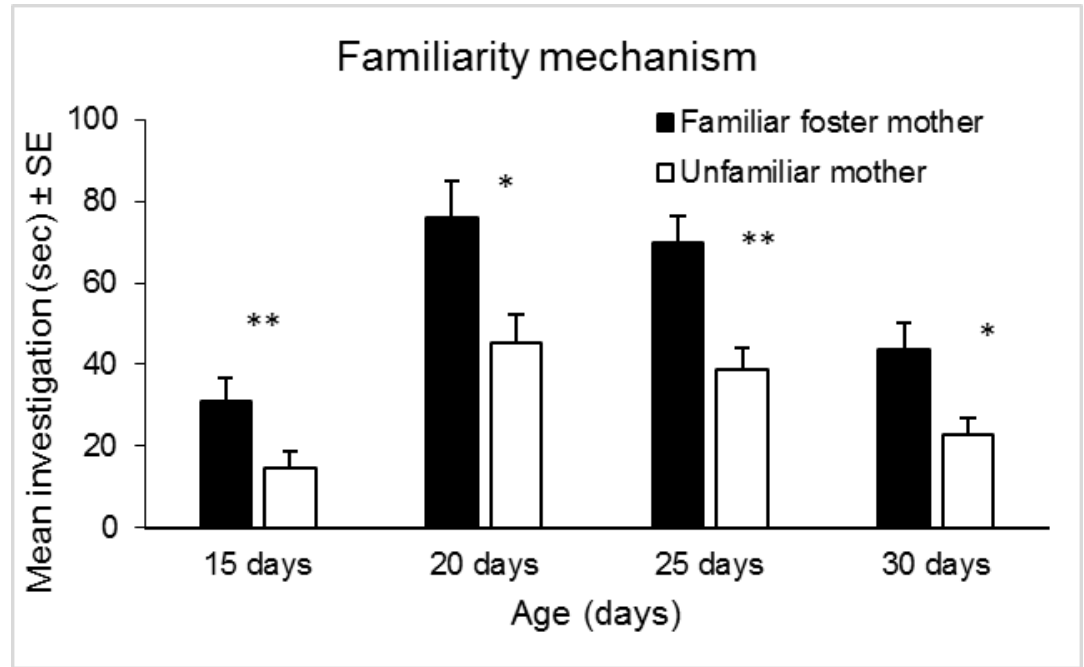

Figure 2. Mean (+SE sec) duration of investigation of odors collected from adult female Belding's ground squirrels by young across early development from 15-30 days of age in the phenotype-matching test. Black bars represent investigation of odor collected from the unfamiliar genetic mother, and open bars represent investigation of odor collected from an unfamiliar unrelated mother. Asterisk indicates significant difference in the duration of investigation of odors $(* p<0.05)$. 


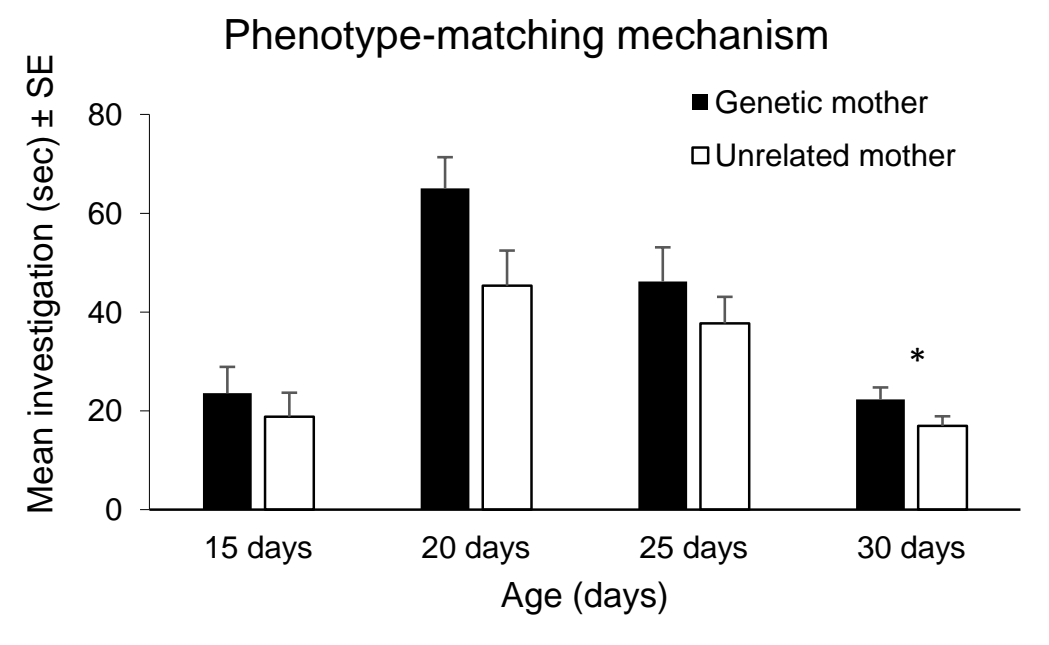


Table 1. Latencies to investigate odors in the Familiarity tests and results of normal-scores test comparing latencies at each age; $N$ was adjusted if a pup did not investigate both stimuli

\begin{tabular}{|l|c|c|c|}
\hline & Familiar foster & Unfamiliar & Normal scores test \\
& $\begin{array}{c}\text { mother, mean sec } \\
\pm \mathrm{SE}(n)\end{array}$ & unrelated mother, & \\
& mean sec $\pm \mathrm{SE}(n)$ & \\
\hline 15 Days & $35.39 \pm 7.61(22)$ & $52.62 \pm 11.55(22)$ & $t(21)=-1.378, p=0.183$ \\
\hline 20 Days & $28.76 \pm 6.61(25)$ & $25.347 \pm 5.98(25)$ & $t(24)=0.350, p=0.729$ \\
\hline 25 Days & $23.76 \pm 5.03(25)$ & $20.262 \pm 4.93(25)$ & $t(24)=0.491, p=0.628$ \\
\hline 30 Days & $10.80 \pm 2.21(20)$ & $14.89 \pm 4.47(20)$ & $t(19)=-0.599, p=0.557$ \\
\hline
\end{tabular}

Table 2. Latencies to investigate odors in the Phenotype-matching tests and results of normal-scores test comparing latencies at each age; $N$ was adjusted if a pup did not investigate both stimuli

\begin{tabular}{|l|c|c|c|}
\hline & Genetic mother, & Unrelated & Normal scores test \\
& mean sec \pm SE $(n)$ & $\begin{array}{c}\text { mother, mean sec } \\
\pm \text { SE }(n)\end{array}$ & \\
\hline 15 Days & $42.69 \pm 7.97(22)$ & $31.74 \pm 5.33(22)$ & $t(21)=1.273, p=0.217$ \\
\hline 20 Days & $15.83 \pm 3.75(26)$ & $33.39 \pm 6.99(26)$ & $t(25)=-1.596, p=0.123$ \\
\hline 25 Days & $19.15 \pm 6.31(26)$ & $17.63 \pm 4.32(26)$ & $t(25)=-0.279, p=0.783$ \\
\hline 30 Days & $23.56 \pm 7.12(20)$ & $9.61 \pm 1.62(20)$ & $t(19)=1.813, p=0.086$ \\
\hline
\end{tabular}




\section{References}

[1] G.J. Gamboa, Kin recognition in social wasps, in: S. Turillazzi, M.J. West-Eberhard, (Eds), Natural History and Evolution of Paper Wasps, Oxford University Press, Oxford, 1996, pp. 161-177.

[2] P. Jaisson, Kinship and fellowship in ants and social wasps, in: P.G. Hepper, (Ed). Kin Recognition, Cambridge University Press, Cambridge, United Kingdom, 1991, pp. 60-93.

[3] B. Waldman, Kin recognition in amphibians, in: P.G. Hepper, (Ed). Kin Recognition, Cambridge University Press, Cambridge, United Kingdom, 1991, pp. 162-219.

[4] B.D. Neff, P.W. Sherman, Nestling recognition via direct cues by parental male bluegill sunfish (Lepomis macrochirus), Animal Cognition 6 (2003) 87-92. doi:10.1007/s10071-003-0166-y.

[5] K.H. Olsén, M. Grahn, J. Lohm, Å. Langefors, MHC and kin discrimination in juvenile Arctic charr, Salvelinus alpinus (L.), Anim. Behav. 56 (1998) 319-327. doi:10.1006/anbe.1998.0837.

[6] H.R. Coffin, J.V. Watters, J.M. Mateo, Odor-based recognition of familiar and related conspecifics: A first test conducted on captive Humboldt penguins (Spheniscus humboldti), Plos One 6 (2011) e25002. doi:10.1371/journal.pone.0025002.

[7] F. Bonadonna, G.A. Nevitt, Partner-specific odor recognition in an antarctic seabird, Science 306 (2004) 835. doi:10.1126/science.1103001.

[8] J.F. Eisenberg, D.G. Kleiman, Olfactory communication in mammals, Annu. Rev. Ecol. Syst. 3 (1972) 1-32. doi:10.1146/annurev.es.03.110172.000245.

[9] R.E. Johnston, Individual odors and social communication: Individual recognition, kin recognition, and scent over-marking, Adv. Study. Behav. 38 (2008) 439-505. doi:10.1016/S0065-3454(08)000090.

[10] J.M. Mateo, Perspectives: Hamilton's legacy: Mechanisms of kin recognition in humans, Ethology 121 (2015) 419-427. doi:10.1111/eth.12358.

[11] J.F. Hare, Group member discrimination by Columbian ground squirrels via familiarity with substrate-borne cues, Anim. Behav. 47 (1994) 803-813. doi:10.1006/anbe.1994.1112. 
[12] Z.T. Halpin, The role of olfactory communication in the social systems of ground-dwelling sciurids, in: J.O. Murie, G.R. Michener, (Eds), The Biology of Ground-dwelling Squirrels, University of Nebraska Press, Lincoln, 1984, pp. 201-225.

[13] V.K. Kivett, J.O. Murie, A.L. Steiner, A comparative study of scent-gland location and related behavior in some northwestern nearctic ground squirrel species (Sciuridae): an evolutionary approach, Can. J. Zool. 54 (1976) 1294-1306.

[14] S. Henkel, A.R. Lambides, A. Berger, R. Thomsen, A. Widdig, Rhesus macaques (Macaca mulatta) recognize group membership via olfactory cues alone, Behav. Ecol. Sociobiol. 69 (2015) 2019-2034. doi:10.1007/s00265-015-2013-y.

[15] B.J. Pitcher, R.G. Harcourt, B. Schaal, I. Charrier, Social olfaction in marine mammals: wild female Australian sea lions can identify their pup's scent, Biol. Lett. 7 (2011) 60-62. doi:10.1098/rsbl.2010.0569.

[16] G.K. Beauchamp, K. Yamazaki, Chemical signalling in mice, Biochem. Soc. Trans. 31 (2003) 147151. doi:10.1042/bst0310147.

[17] J.M. Mateo, Kin-recognition abilities and nepotism as a function of sociality, Proc. R. Soc. B-Biol. Sci. 269 (2002) 721-727. doi:10.1098/rspb.2001.1947.

[18] J.M. Mateo, The nature and representation of individual recognition cues in Belding's ground squirrels, Anim. Behav. 71 (2006) 141-154. doi:10.1016/j.anbehav.2005.04.006.

[19] J.M. Mateo, Recognition systems and biological organization: The perception component of recognition, Ann. Zool. Fenn. 41 (2004) 729-745.

[20] W.D. Hamilton, The genetical evolution of social behaviour. II, J. Theor. Biol. 7 (1964) 17-52. doi:10.1016/0022-5193(64)90039-6.

[21] M.D. Beecher, Signature systems and kin recognition, Am. Zool. 22 (1982) 477-490. doi:10.1093/icb/22.3.477

[22] N.D. Tsutsui, Scents of self: The expression component of self/non-self recognition systems, Ann. Zool. Fenn. 41 (2004) 713-727. 
[23] W.G. Holmes, P.W. Sherman, The ontogeny of kin recognition in two species of ground squirrels, Am. Zool. 22 (1982) 491-517. doi:10.1093/icb/22.3.491.

[24] G.J. Gamboa, H.K. Reeve, W.G. Holmes, Conceptual issues and methodology in kin-recognition research: A critical discussion, Ethology 88 (1991) 109-127. doi:10.1111/j.1439-0310.1991.tb00267.x.

[25] A.R. Blaustein, M. Bekoff, T.J. Daniels, Kin recognition in vertebrates (excluding primates):

Mechanisms, functions and future research, in: D.J.C. Fletcher, C.D. Michener, (Eds), Kin

Recognition in Animals, John Wiley \& Sons, Inc., New York, 1987, pp. 333-357.

[26] A.R. Blaustein, Ecological correlates and potential functions of kin recognition and kin association in anuran larvae, Behav. Genet. 18 (1988) 449-464. doi:10.1007/BF01065514.

[27] J. Komdeur, B.J. Hatchwell, Kin recognition: function and mechanism in avian societies, Trends Ecol. Evol. 14 (1999) 237-241. doi:10.1016/S0169-5347(98)01573-0.

[28] D.W. Pfennig, Cannibalistic tadpoles that pose the greatest threat to kin are most likely to discriminate kin, Proc. R. Soc. B-Biol. Sci. 266 (1999) 57-61. doi:10.1098/rspb.1999.0604.

[29] P.W. Sherman, Nepotism and the evolution of alarm calls, Science 197 (1977) 1246-1253. doi:10.1126/science.197.4310.1246.

[30] L. Greenberg, Kin recognition in the sweat bee, Lasioglossum zephyrum, Behav. Genet. 18 (1988) 425-438. doi:10.1007/BF01065512.

[31] P.G. Hepper, Kin recognition - Functions and mechanisms. A Review, Biol. Rev. Camb. Philos. Soc. 61 (1986) 63-93. doi:10.1111/j.1469-185X.1986.tb00427.x.

[32] P.C. Brunjes, J.R. Alberts, Olfactory stimulation induces filial preferences for huddling in rat pups, J. Comp. Physiol. Psychol. 93 (1979) 548-555.

[33] A. Duveau, F. Godinot, Influence of the odorization of the rearing environment on the development of odor-guided behavior in rat pups, Physiol. Behav. 42 (1988) 265-270. doi:10.1016/00319384(88)90080-7.

[34] G. Gerlach, N. Lysiak, Kin recognition and inbreeding avoidance in zebrafish, Danio rerio, is based on phenotype matching, Anim. Behav. 71 (2006) 1371-1377. doi:10.1016/j.anbehav.2005.10.010. 
[35] P.G. Hepper, Sibling recognition in the rat, Anim. Behav. 31 (1983) 1177-1191. doi:10.1016/S00033472(83)80024-4.

[36] V. Mekosh-Rosenbaum, W.J. Carr, J.L. Goodwin, P.L. Thomas, A. Dver, C.J. Wysocki, Agedependent responses to chemosensory cues mediating kin recognition in dogs (Canis familiaris), Physiol. Behav. 55 (1994) 495-499. doi:10.1016/0031-9384(94)90106-6.

[37] C. Janus, The development of responses to naturally occurring odours in spiny mice Acomys cahirinus, Anim. Behav. 36 (1988) 1400-1406. doi:10.1016/S0003-3472(88)80210-0.

[38] N.G. Solomon, T. Rumbaugh, Odor preferences of weanling and mature male and female pine voles, J. Chem. Ecol. 23 (1997) 2133-2143. doi:10.1023/B:JOEC.0000006434.97821.fa.

[39] W.J. Loughry, G.F. McCracken, Factors influencing female-pup scent recognition in Mexican freetailed bats, J. Mammal. 72 (1991) 624-626. doi:10.2307/1382150

[40] A.C. Spokes, E.S. Spelke, Children's expectations and understanding of kinship as a social category, Front. Psychol. 7 (2016). doi:10.3389/fpsyg.2016.00440.

[41] P.G. Hepper, Parental recognition in the rat, Q. J. Exp. Psychol. Sect. B 38 (1986) 151-160.

[42] J.M. Mateo, Development of individually distinct recognition cues, Dev. Psychobiol. 48 (2006) 508519. doi:10.1002/dev.20156.

[43] A.R. Blaustein, R.K. O'Hara, D.H. Olson, Kin preference behaviour is present after metamorphosis in Rana cascadae frogs, Anim. Behav. 32 (1984) 445-450. doi:10.1016/S0003-3472(84)80280-8.

[44] M.D. Breed, E.A. Leger, A.N. Pearce, Y.J. Wang, Comb wax effects on the ontogeny of honey bee nestmate recognition, Anim. Behav. 55 (1998) 13-20. doi:10.1006/anbe.1997.0581.

[45] G.J. Gamboa, H.K. Reeve, I.D. Ferguson, T.L. Wacker, Nestmate recognition in social wasps: the origin and acquisition of recognition odors, Anim. Behav. 34 (1986) 685-695. doi:10.1016/S00033472(86)80053-7.

[46] L.M. Panek, G.J. Gamboa, K.E. Espelie, The effect of a wasp's age on its cuticular hydrocarbon profile and its tolerance by nestmate and non-nestmate conspecifics (Polistes fuscatus, Hymenoptera: Vespidae), Ethology 107 (2001) 55-63. doi:10.1046/j.1439-0310.2001.00633.x. 
[47] S.P. Sharp, B.J. Hatchwell, Development of family specific contact calls in the long-tailed tit Aegithalos caudatus, Ibis 148 (2006) 649-656. doi:10.1111/j.1474-919X.2006.00568.x.

[48] L. Amo, G. Tomas, D. Parejo, J.M. Aviles, Are female starlings able to recognize the scent of their offspring?, Plos One 9 (2014) 6. doi:10.1371/journal.pone.0109505.

[49] M.D. Beecher, I.M. Beecher, S. Hahn, Parent-offspring recognition in bank swallows. II.

Development and acoustic basis, Anim. Behav. 29 (1981) 95-101. doi:10.1016/S0003-3472(81)80156X.

[50] P.W. Sherman, Kinship, demography, and Belding's ground squirrel nepotism, Behav. Ecol. Sociobiol. 8 (1981) 251-259. doi:10.1007/BF00299523.

[51] S.H. Jenkins, B.D. Eshelman, Spermophilus beldingi, Mammalian Species 221 (1984) 1-8. doi:10.2307/3503911.

[52] P.W. Sherman, M.L. Morton, Demography of Belding's ground squirrels, Ecology 65 (1984) 16171628. doi:10.2307/1939140.

[53] K.E. Holekamp, Natal dispersal in Belding's ground squirrels (Spermophilus beldingi), Behav. Ecol. Sociobiol. 16 (1984) 21-30. doi:10.1007/BF00293100.

[54] W.D. Hamilton, The genetical evolution of social behaviour. I, J. Theor. Biol. 7 (1964) 1-16. doi:10.1016/0022-5193(64)90038-4.

[55] W.G. Holmes, J.M. Mateo, Kin Recognition in Rodents - Issues and Evidence, in: J.O. Wolff, P.W. Sherman, (Eds), Rodent Societies, University of Chicago Press, Chicago, 2007, pp. 216-228.

[56] J.M. Mateo, W.G. Holmes, Cross-fostering as a means to study kin recognition, Anim. Behav. 68 (2004) 1451-1459. doi:10.1016/j.anbehav.2004.01.017.

[57] B. Waldman, P.C. Frumhoff, P.W. Sherman, Problems of kin recognition, Trends in Ecology and Evolution 3 (1988) 8-13. doi:10.1016/0169-5347(88)90075-4.

[58] J.M. Mateo, The causal role of odours in the development of recognition templates and social preferences, Anim. Behav. 77 (2009) 115-121. doi:10.1016/j.anbehav.2008.09.015. 
[59] J.M. Mateo, Self-referent phenotype matching and long-term maintenance of kin recognition, Anim. Behav. 80 (2010) 929-935. doi:10.1016/j.anbehav.2010.08.019.

[60] G.J. Gamboa, K.A. Berven, R.A. Schemidt, T.G. Fishwild, K.M. Jankens, Kin recognition by larval wood frogs (Rana sylvatica): effects of diet and prior exposure to conspecifics, Oecologia 86 (1991) 319-324. doi:10.1007/BF00317596.

[61] P.G. Hepper, Recognizing kin: ontogeny and classification, in: P.G. Hepper, (Ed). Kin Recognition, Cambridge University Press, Cambridge, United Kingdom, 1991, pp. 259-288.

[62] C.M. Leonard, Developmental changes in olfactory bulb projections revealed by degeneration argyrophilia, J. Comp. Neur. 162 (1975) 467-486. doi:10.1002/cne.901620405.

[63] P.C. Brunjes, L.L. Frazier, Maturation and plasticity in the olfactory system of vertebrates, Brain Res. Rev. 11 (1986) 1-45. doi:10.1016/0165-0173(86)90008-1.

[64] M. Halpern, The organization and function of the vomeronasal system, Annu. Rev. Neurosci. 10 (1987) 325-362.

[65] A.L. Steiner, Body-rubbing, marking, and other scent-related behavior in some ground squirrels (Sciuridae), a descriptive study, Can. J. Zool. 52 (1974) 889-906.

[66] W.G. Holmes, Temporal aspects in the development of Belding's ground squirrels' litter-mate preferences, Anim. Behav. 53 (1997) 1323-1336. doi:10.1006/anbe.1996.0367.

[67] W.G. Holmes, Parent-offspring recognition in mammals: A proximate and ultimate perspective, in: N.A. Krasnegor, R.S. Bridges, (Eds), Mammalian parenting: Biochemical, neurobiological, and behavioral determinants, Oxford University Press, New York, NY, USA, 1990, pp. 441-460.

[68] R.B. Darlington, Regression and Linear Models, McGraw Hill, NY, 1990.

[69] R.B. Darlington, A normal-scores alternative to the Wilcoxon test., http://node101.psych.cornell.edu/Darlington/normscor.htm, 1996 (accessed 11/4/2016).

[70] W.G. Holmes, The development of littermate preferences in juvenile Belding's ground squirrels, Anim. Behav. 48 (1994) 1071-1084. doi:10.1006/anbe.1994.1341. 
[71] G.R. Michener, Kin identification, matriarchies, and the evolution of sociality in ground-dwelling sciurids, in: J.F. Eisenberg, D.G. Kleiman, (Eds), Advances in the Study of Mammalian Behavior, American Society of Mammalogists, Shippensburg, PA, 1983, pp. 528-572.

[72] W.G. Holmes, Identification of paternal half-siblings by captive Belding's ground squirrels, Anim. Behav. 34 (1986) 321-327. doi:10.1016/S0003-3472(86)80099-9.

[73] J.M. Mateo, Kin recognition in ground squirrels and other rodents, J. Mammal. 84 (2003) 11631181. doi:10.1644/BLe-011.

[74] P.W. Sherman, Reproductive competition and infanticide in Belding's ground squirrels and other animals, in: R.D. Alexander, D.W. Tinkle, (Eds), Natural Selection and Social Behaviour: Recent Research and New Theory, Chiron Press, New York, 1981, pp. 311-331.

[75] R. Dawkins, The Extended Phenotype, W. H. Freeman, San Francisco, 1982.

[76] P.W. Sherman, H.K. Reeve, D.W. Pfennig, Recognition systems, in: J.R. Krebs, N.B. Davies, (Eds), Behavioural Ecology: An Evolutionary Approach, 4 ed, Blackwell Scientific Publications, Oxford, United Kingdom, 1997, pp. 69-96.

[77] J.B. Silk, Nepotistic cooperation in non-human primate groups, Philos. Trans. R. Soc. B-Biol. Sci. 364 (2009) 3243-3254. doi:10.1098/rstb.2009.0118.

[78] R.C. Van Horn, S.A. Wahaj, K.E. Holekamp, Role-reversed nepotism among cubs and sires in the spotted hyena (Crocuta crocuta), Ethology 110 (2004) 413-426. doi:10.1111/j.14390310.2004.00984.x.

[79] J.W.Y. Wong, J. Meunier, C. Lucas, M. Kolliker, Paternal signature in kin recognition cues of a social insect: concealed in juveniles, revealed in adults, Proc. R. Soc. B-Biol. Sci. 281 (2014) 7. doi:10.1098/rspb.2014.1236. 